\title{
Effect of Lactobacillus reuteri Administration on Wrinkle Formation and Type I Procollagen Levels in UVB-Exposed Male Balb/c Mice (Mus musculus)
}

\author{
Ivanna Valentina ${ }^{1}$, Achadiyani $^{2}$, Sunarjati Sudigdo Adi ${ }^{3}$, Ronny Lesmana ${ }^{4,5}$, Reni Farenia ${ }^{6}$ \\ ${ }^{1}$ Postgraduate Program of Anti-aging and Aesthetics Medicine, Faculty of Medicine, Universitas Padjadjaran, Bandung, Indonesia \\ ${ }^{2}$ Cell Biology Division, Department of Biomedical Science, Faculty of Medicine, Universitas Padjadjaran, Jatinangor, Indonesia \\ ${ }^{3}$ Microbiology Division, Department of Biomedical Science, Faculty of Medicine, Universitas Padjadjaran, Jatinangor, Indonesia \\ ${ }^{4}$ Physiology Division, Department of Biomedical Science, Faculty of Medicine, Universitas Padjadjaran, Jatinangor, Indonesia \\ ${ }^{5}$ Physiology Molecular Laboratory, Biological Activity Division, Central Laboratory, Universitas Padjadjaran, Jatinangor, \\ Indonesia \\ ${ }^{6}$ Indonesian Physiological Society, Faculty of Medicine, Universitas Padjadjaran, Jatinangor, Indonesia
}

Background: Chronic Ultraviolet B (UVB) exposure causes oxidative stress that may induce damages to the collagen matrix and thus plays a role in the wrinkle formation. Lactobacillus reuteri is a probiotic that may exerts antioxidant effects, thus helping to reduce damages caused by UVB-induced oxidative stress in the skin.

Materials and Methods: Twenty-eight male Balb/c mice were divided equally into control group, UVB radiation only group, oral $L$. reuteri supplementation only group, and UVB radiation with oral $L$. reuteri supplementation group. UVB irradiation was given 3 times a week (100 seconds/exposure, within $3 \mathrm{~cm}$ distance) for 10 weeks, with a total dose of $166 \mathrm{~mJ} / \mathrm{cm}^{2}$. Oral L. reuteri supplementation $(0.2 \mathrm{~mL}, 108 \mathrm{CFU})$ was provided every morning after meal via orogastric feeding tube for 10 weeks. Wrinkle formation on the dorsal skin of the mice was evaluated in accordance with the Bissett method and type I procollagen levels was evaluated by western blotting.

Results: In comparison with the group receiving only UVB irradiation, the group receiving probiotic and UVB irradiation showed significantly lower wrinkle scores (Group 1 vs. Group 3, $2.50 \pm 0.55$ vs. $1.00 \pm 0,00 ; p<0.05$ ) and significantly higher type I procollagen levels (Group 1 vs. Group 3, $0.88 \pm 0.36$ vs. $1.92 \pm 0.46 ; p<0.05$ ).

Conclusion: Results of the current study showed that $L$. reuteri supplementation may reduce wrinkle formation and increase type I procollagen production in UVB-exposed dorsal skin of male Balb/c mice.

Keywords: Lactobacillus reuteri, type I procollagen, photoaging, wrinkles, ultraviolet B

\section{Introduction}

Aging is a process where the structural integrity and physiological function of every organ in the human body will be lost over time. ${ }^{1-3}$ Skin is one of the main and most visible indicator of age in the human body. ${ }^{1}$ Cumulative intrinsic and extrinsic factors causes progressive changes in the structure and physiology of all skin layers, which

Date of submission: June 23, 2019

Last Revised: November 1, 2019

Accepted for publication: November 1, 2019

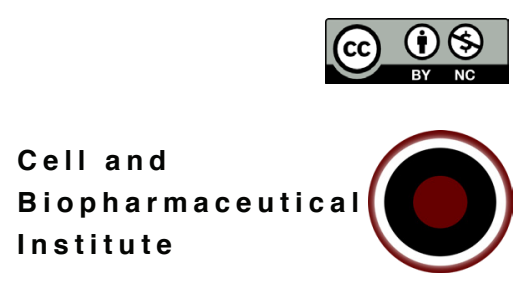

Corresponding Author:

Ivanna Valentina

Postgraduate Program of Anti-aging and Aesthetics Medicine

Faculty of Medicine, Universitas Padjadjaran

J. Eijkman No. 38, Bandung 40161, Indonesia

e-mail: ivannavalentina91@gmail.com 
in return will change the external appearance of the skin, especially in areas with more sun exposure.,

Ultraviolet (UV) B irradiation is one of the main external factors that influences extrinsic skin aging. ${ }^{6}$ The connective tissues structure in dermis are mostly made of collagen fibers, and chronic UV exposure will induce oxidative stress that play a role in damaging this extracellular collagen matrix. These damages to the skin architecture will manifest as rough, dull skin, and wrinkles. ${ }^{7}$

Activator protein-1 (AP-1) and transforming growth factor- $\beta$ (TGF- $\beta$ ) are known to regulate the collagen production by fibroblast. ${ }^{8}$ UV irradiation will increase intracellular reactive oxygen species (ROS) production. ROS will then induce the mitogen-activated protein kinase (MAPK) signaling system to activate the transcription factor nuclear factor-kappa $\mathrm{B}(\mathrm{NF}-\mathrm{\kappa B})$ and $\mathrm{AP}-1$. AP-1 may reduce the synthesis of procollagen type III and I by inhibiting the TGF- $\beta$ signaling. Meanwhile, activation of transcription factor AP-1 and NF- $\mathrm{KB}$ also upregulates the expression of matrix metalloproteinase (MMP). MMP in the dermal extracellular matrix plays a role in increasing collagen and elastin degradation. . $^{911}$

In addition to increasing matrix degradation enzyme productions, chronic UV exposure may also reduce the expression of collagen precursor (procollagen) type III and I in photoaged skin, thus disrupting new collagen formation. Reduced procollagen expression may be caused by an irreversible UV-induced impairment in the mechanisms regulating the synthesis and degradation of collagen in dermal fibroblast. Damaged extracellular matrix may also send a signal to inhibit procollagen synthesis by the fibroblast. $^{7}$

Recent studies found that probiotic supplementation can be useful to protect the skin from UV-induced damage. Lactobacilli species produces exopolysaccharides (EPS) and superoxide dismutase (SOD) that may confer a protection from peroxide free radicals. The antioxidant effect of probiotic may help to restore the balance between the production of free radicals and antioxidants. The restored normal redox balance in the skin is expected to slow the photoaging process. ${ }^{12}$

An in vitro study found that Lactobacillus reuteri has the ability to scavenge free radicals, and may also help increase antioxidant enzymes production. ${ }^{13}$ L. reuteri supplementation in diabetic mice was found to increase the antioxidant capacity. ${ }^{14}$ Studies also found that $L$. reuteri supplementation may inhibit hepatic ${ }^{15}$, human myeloid-leukemia derived cells ${ }^{16}$, and human monocytes and macrophages MAPK/NF- $\mathrm{KB}$ signaling mechanism, thus reducing the activity of transcription factor NF- $\kappa \mathrm{B}$ and AP-1. ${ }^{17}$ Mice supplemented with oral L. reuteri also showed increased sebocytogenesis, dermal thickening and folliculogenesis manifested as brighter skin and thicker hair growth. ${ }^{18,19}$

Consequently, the researcher is interested in studying the photoprotective effect of $L$. reuteri supplementation by evaluating wrinkle formations and changes in type I procollagen levels in UVB-exposed dorsal skin of male $\mathrm{Balb} / \mathrm{c}$ mice.

\section{Materials and methods}

\section{Experimental Animals}

The experimental protocol was reviewed and approved by the Health Research Ethics Committee of Faculty of Medicine, Universitas Padjajaran University (No. 86/UN6. $\mathrm{KEP} / \mathrm{EC} / 2019$ ). Twenty-eight male Balb/c mice (4-6 week old) were purchased from the animal laboratory of PT. Biofarma (Bandung, Indonesia). Plastic cages with grated stainless steel cover were used to house the mice. The room temperature was kept at $22-25^{\circ} \mathrm{C}$ with a 12 -h light/ dark cycle. The mice were provided with drinking water and standard chow diet ad libitum during the experimental period.

The experimental mice were randomly divided into four groups ( 7 mice in each group) after a period of adaptation. The groups were: the control group, the mice was treated without probiotic or UVB radiation as a standard against which to measure difference among experimental (Group 0); the group that was given UVB radiation only (Group 1); the group that was given $108 \mathrm{CFU}$ oral $L$. reuteri supplementation only (Group 2); and the group that was given UVB radiation with $108 \mathrm{CFU}$ oral $L$. reuteri supplementation (Group 3). All mice were then shaved to clear the dorsal skin from any hair.

The inclusion criteria were 4-6 week old male Balb/c mice with body weight between 20-30 grams, and normal behavior/activities. The exclusion criteria were mice who refused to eat the standard chow diet during the experimental period, and mice with extreme weight loss, perished, or had skin infection during the course of treatment. At the end of the study period, 4 mice were excluded (1 from each group, 2 due to skin infections and 2 due to abnormal body weight), leaving only 24 for further analysis. 


\section{UV Radiation}

Previously described methods was followed to perform the UVB irradiation. ${ }^{20-22}$ Mice from Group 1 and Group 3 were exposed to UVB light (311 nm, Kernel KN-4003, $0.07 \mathrm{~mW}$ / $\mathrm{cm}^{2}$, Xuzhou, China) 3 times a week (100 seconds/exposure, within $3 \mathrm{~cm}$ distance) for 10 weeks, with a total dose of 166 $\mathrm{mJ} / \mathrm{cm}^{2}$. The animals were irradiated within their cage.

\section{Oral L. reuteri Supplementation}

Oral $L$. reuteri supplementation was provided for all mice in Group 2 and Group 3 groups. Liquid probiotic $(0.2 \mathrm{~mL}, 108$ $\mathrm{CFU}$ ) was provided every morning after meal via orogastric feeding tube for 10 weeks.

\section{Evaluation of Wrinkles Formation}

Wrinkle formation was evaluated in accordance with the method of Bissett et al. ${ }^{23}$ The dorsal skin of the mice were photographed after 10 weeks. The wrinkles were then evaluated with respect to their size and depths. Grade 0 indicated dynamic fine lines, grade 1 indicated dynamic shallow coarse wrinkles, grade 2 indicated permanent deep coarse wrinkles, and grade 3 indicated permanent deeper coarse wrinkles.

\section{Western Blotting}

As much as $10 \%$ sodium dodecyl sulfate-polyacrylamide gel electrophoresis (SDS-PAGE) was used to separate the proteins prepared from mice skin tissues for 1.5 hours. The proteins were then transferred to a nitrocellulose membrane for 30 minutes at $200 \mathrm{~mA}$. Membrane was then incubated overnight at $4^{\circ} \mathrm{C}$ using the anti-procollagen I (Catalogue

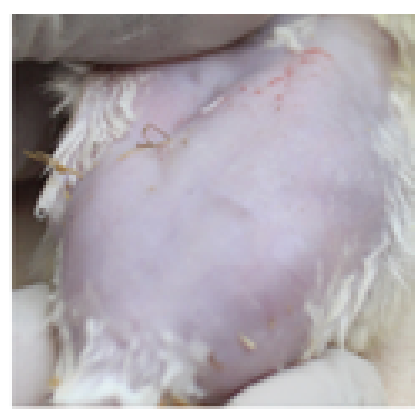

Group 0

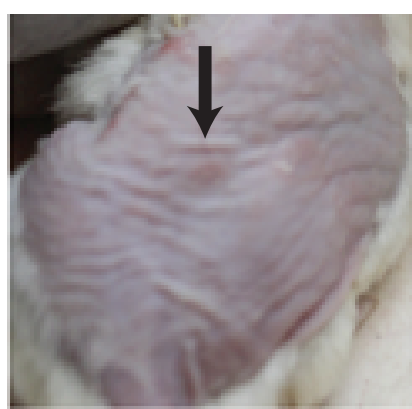

Group 1

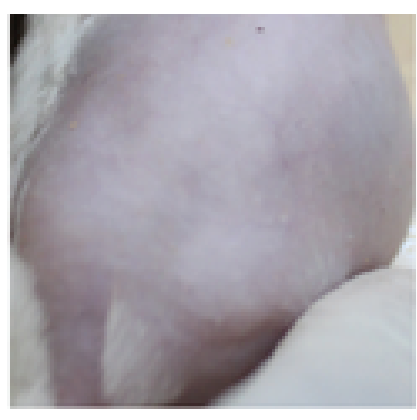

Group 2

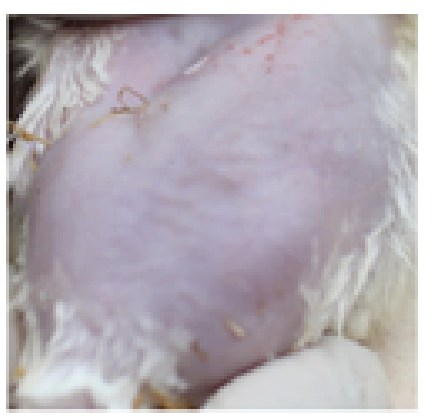

Group 3

\#PA5-29569, Thermo Scientific, Massachusetts, USA) and anti- $\beta$-actin antibody (Catalogue \#MA5-15739, Thermo Scientific) as primary antibody. The membranes were incubated with horseradish peroxidase-conjugated goat anti-rabbit IgG (Catalogue \#31460, Thermo Scientific) as secondary antibody in bovine serum albumin $0.10 \%$ solution for 90 minutes at room temperature after being washed using PBS $0.1 \%$ as washing buffer. Chemiluminescence substrate was then used to incubate the membrane blots for 5 minutes. Digital image-J software was used to analyze the results of membrane detection.

\section{Statistical Analysis}

Statistical analysis was performed using SPSS 16.0 (SPSS Inc, Chicago, USA). The difference in Bissett scores between all the study groups was analyzed using Mann-Whitney test. The differences in procollagen I levels between all the study groups was analyzed using one-way ANOVA. A post-hoc test of the variance and significance levels were then performed. Results were reported as mean $\pm \mathrm{SD}$. A $p$-value $<0.05$ was considered significant.

\section{Results}

Twenty-eight mice were randomly divided into 4 groups. Four mice were excluded by the end of the study period ( 1 from each group, 2 due to skin infections and 2 due to abnormal body weight), leaving only 24 for further analysis. Data from the 4 mice was considered as outliers, thus they were excluded to avoid statistical bias. Figure 1 showed the shaved dorsal skin of mice from each group at the end of the study.

Figure 1. Shaved dorsal skin of mice from group 0, 1, 2 and 3 at the end of study. The arrow reflected to the wrinkle appearance. 
Table 1. Wrinkle scores and type 1 procollagen levels for all study groups. ( $\mathrm{n}=6$, in each group).

\begin{tabular}{lcccc}
\hline & Group & Mean \pm SD & Median (min-max) & $p$-value \\
\hline Wrinkle score (Bissett) & 0 & $0.00 \pm 0.00$ & $0(0-0)$ & $<0.001^{*}$ \\
& 1 & $2.50 \pm 0.55$ & $2.5(2-3)$ & \\
& 2 & $0.00 \pm 0.00$ & $0(0-0)$ & \\
\hline Type 1 procollagen & 3 & $1.00 \pm 0.00$ & $1(1-1)$ & \\
& 0 & $1.73 \pm 0.59$ & $1.62(1.13-2.47)$ & $0.009^{* *}$ \\
& 1 & $0.88 \pm 0.36$ & $0.71(0.59-1.39)$ & \\
& 2 & $1.24 \pm 0.60$ & $1.07(0.78-2.38)$ & \\
& 3 & $1.92 \pm 0.46$ & $1.76(1.49-2.57)$ & \\
\hline
\end{tabular}

*Kruskal-Wallis test, significant when $p<0.05$. **One-way ANOVA, significant when $p<0.05$.

\section{Wrinkle Scores}

Mice in Group 0 and Group 2 showed mean wrinkle scores of $0.00 \pm 0.00$. Meanwhile, Group 1 showed mean wrinkle scores of $2.50 \pm 0.55$ and Group 3 showed mean wrinkle scores of $1.00 \pm 0.00$ (Table 1). Group 1 showed the highest mean wrinkle scores, whereas Group 0 and Group 2 both showed the lowest mean wrinkle scores (Figure 2A).

Statistical analysis found that the group receiving UVB irradiation and probiotic supplementation showed significantly lower wrinkle scores in comparison with the group receiving only UVB irradiation (Group 3 vs. Group $1,1.00 \pm 0.00$ vs. $2.50 \pm 0.55 ; p<0.05$ ). The wrinkle scores between the control group and the group receiving only UVB irradiation (Group 0 vs. Group 1, $0.00 \pm 0.00$ vs.

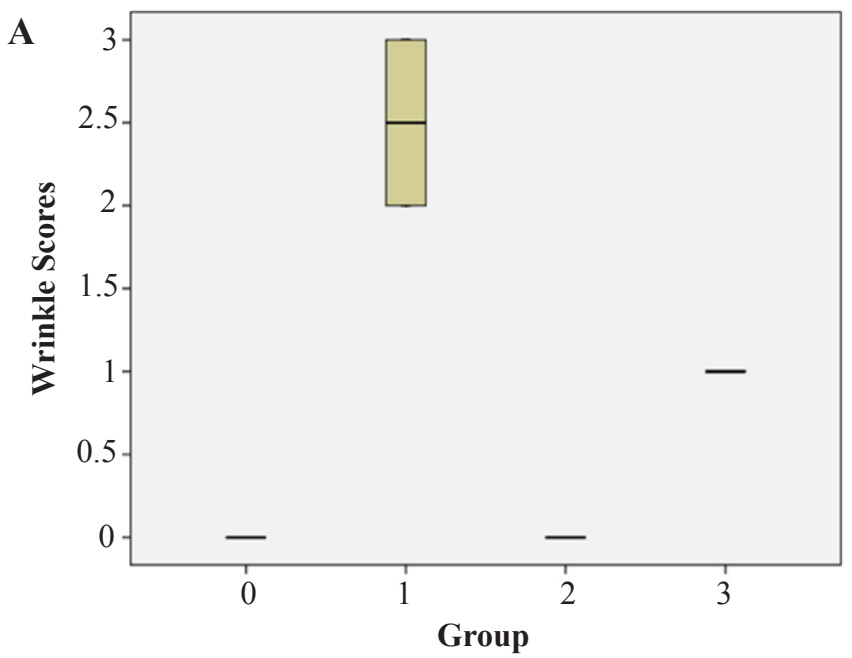

Figure 2. Boxplot graph of Bissett wrinkle scores (A) and type 1 procollagen levels (B) in all treatment groups.

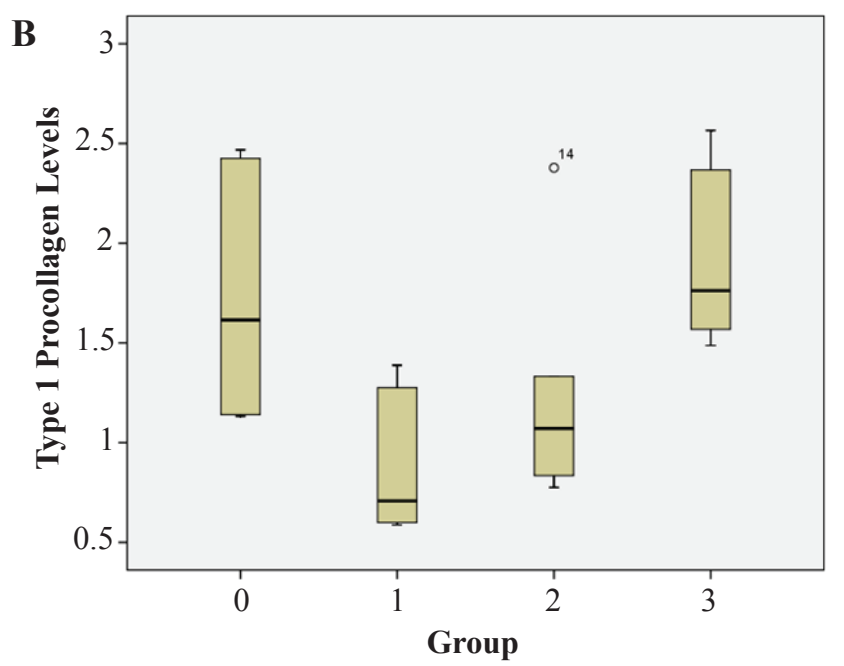

$2.50 \pm 0.55 ; p<0.05)$, control group and the group receiving UVB irradiation with probiotic supplementation (Group 0 vs. Group 3, $0.00 \pm 0.00$ vs. $1.00 \pm 0.00 ; p<0.05)$, the group receiving only UVB irradiation and the group receiving only probiotic (Group 1 vs. Group 2, $2.50 \pm 0.55$ vs. $0.00 \pm 0.00 ; p<0.05$ ), and between the group receiving only probiotic and the group receiving UVB irradiation with probiotic supplementation (Group 2 vs. Group 3, 0.00 \pm 0.00 vs. $1.00 \pm 0.00 ; p<0.05)$ also showed significant differences (Table 2).

\section{Type 1 Procollagen Levels}

Mean type 1 procollagen levels of the mice was $1.73 \pm 0.59$ in Group $0,0.88 \pm 0.36$ in the Group $1,1.24 \pm 0.60$ in the 
Table 2. Comparison of wrinkle scores between treatment groups.

\begin{tabular}{cccc}
\hline \multirow{2}{*}{ Group } & \multicolumn{3}{c}{ Wrinkle Score } \\
\cline { 2 - 4 } & $\mathbf{1}$ & $\mathbf{2}$ & $\mathbf{3}$ \\
\hline $\mathbf{0}$ & $0.002^{*}$ & 1 & $0.001^{*}$ \\
$\mathbf{1}$ & - & $0.002^{*}$ & $0.002^{*}$ \\
$\mathbf{2}$ & & - & $0.001^{*}$ \\
\hline
\end{tabular}

*Mann-Whitney test, significant when $p<0.05$.

Group 2, and $1.92 \pm 0.46$ in the Group 3 (Table 1). The highest mean type 1 procollagen level was reported from the Group 3, whereas the lowest was reported from the Group 1 (Figure 2B).

Statistical analysis found that the group receiving UVB irradiation and probiotic supplementation showed significantly higher type 1 procollagen level in comparison with the group receiving only UVB irradiation (Group 3 vs. Group 1, $1.92 \pm 0.46$ vs. $0.88 \pm 0.36 ; p<0.05)$. Analysis also found significant differences in type 1 procollagen level between the control group and the group receiving only UVB irradiation (Group 0 vs. Group 1, $1.73 \pm 0.59$ vs. $0.88 \pm 0.36 ; p<0.05)$, and between the group receiving only probiotic supplementation and the group receiving UVB irradiation with probiotic supplementation (Group 2 vs. Group 3, $1.24 \pm 0.60$ vs. $1.92 \pm 0.46$; $p<0.05$ ) (Table 3). Meanwhile, Figure 3 showed the result of western blot for type 1 procollagen and the quantification of ratio that is normalized by $\beta$-Actin.

\section{Discussion}

UVB irradiation is one of the main factor that induces wrinkle formation on human skin. ${ }^{6,9}$ Probiotic is a biological treatment that may help protecting the skin from the effects of photoaging. ${ }^{12,24,25}$ In the current study, L. reuteri supplementation was provided to UVB-irradiated mice to prove the efficacy of probiotic in protecting the skin from the effect of photoaging, specifically to increase collagen production and reduce wrinkle formation.

At the end of the study period, all mice from the control group and the group that received no UVB irradiation showed no wrinkle formation. Meanwhile, all mice from the groups that received UVB irradiation showed various degrees of wrinkle formations, where mice from the group
Table 3. Comparison of type 1 procollagen levels between treatment groups.

\begin{tabular}{cccc}
\hline \multirow{2}{*}{ Group } & \multicolumn{3}{c}{ Type 1 Procollagen Levels } \\
\cline { 2 - 4 } & $\mathbf{1}$ & $\mathbf{2}$ & $\mathbf{3}$ \\
\hline $\mathbf{0}$ & $0.009^{*}$ & 0.113 & 0.536 \\
$\mathbf{1}$ & - & 0.229 & $0.002^{*}$ \\
$\mathbf{2}$ & & - & $0.033^{*}$ \\
\hline
\end{tabular}

*Post hoc LSD, significant when $p<0.05$.

receiving only UVB irradiation showed significantly higher wrinkle scores in comparison with the group receiving UVB irradiation with probiotic supplementation. This supported the results of previous studies where UVB irradiation was found to play a role in inducing wrinkle formation. Chronic UV irradiation may cause changes in extracellular matrix (ECM), such as reduced procollagen expression, increased collagen damage. Such changes may reduce skin elasticity and disrupt the structural scaffolding of the skin, thus causing wrinkle formation. ${ }^{26,27}$

The current study has established that probiotic supplementation may help protecting the skin from UVBinduced wrinkle formation. Probiotic was a novel method

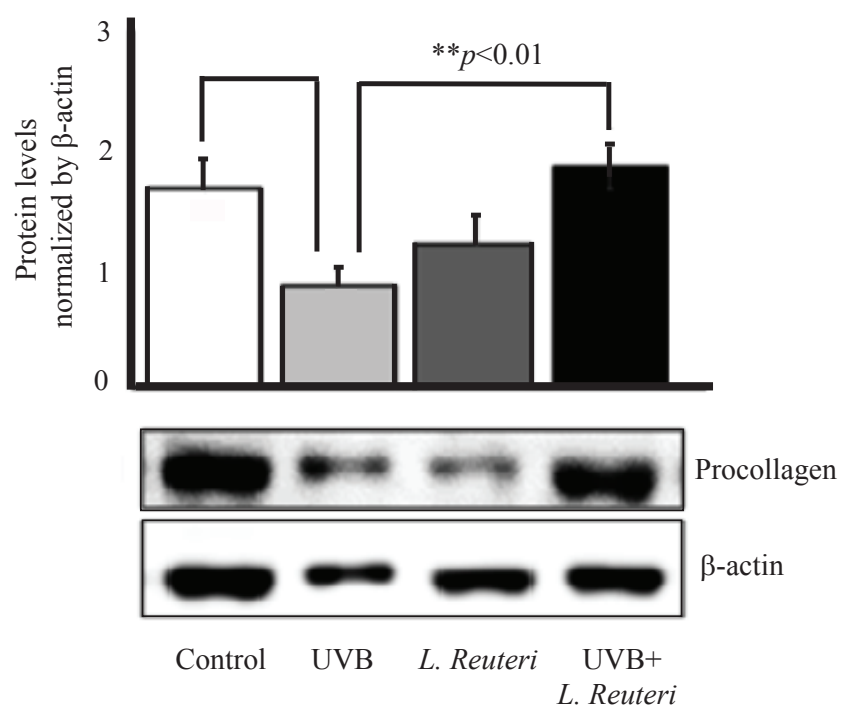

Figure 3. Results of western blot and the quantification of ratio (normalized by $\beta$-Actin) showing the net changes of type 1 procollagen expression. Bars represent the means of the ratios \pm SEM $(n=6)$. 
that may help to prevent or slow the photoaging process, and also to reduce protodamage-related skin changes by restoring the balance between the production of free radicals and antioxidants in human skin. ${ }^{12}$ Probiotics have been shown to produce a number of bioactive molecules that work as antioxidants through a number of different mechanisms, such as the production of EPS and SOD. ${ }^{24,25}$ Previous study found that $L$. acidophilus supplementation may effectively inhibit UVB-induced wrinkle formation by downregulating MMP production, thus reducing collagen degradation in the skin. ${ }^{28}$ Meanwhile, another study found that oral $L$. plantarum supplementation in UVB-exposed hairless mice may reduce the amount and depth of wrinkles in comparison with the control group. ${ }^{29}$ Oral intakes of L. plantarum HY7714 in human subjects also showed beneficial effects such as increasing skin moisture, decreasing the depth of existing wrinkles and improving the overall skin gloss and elasticity $^{30}$, while oral intakes of $L$. reuteri were reported to increase melanin and decrease Trans-Epidermal Water Loss (TEWL) in the facial skin of Korean women. ${ }^{31}$

Among all treatment groups, the group receiving only UVB irradiation showed the lowest mean type 1 procollagen level, and the statistical analysis found a significant correlation in type 1 procollagen level between the control group and the group receiving only UVB radiation. This results confirmed the effect of UVB exposure in inducing the downregulation of type 1 procollagen production in the skin, similar to the results obtained in previous studies. Studies found that UV radiation may cause an irreversible damage to the cellular and molecular mechanism regulating collagen synthesis and degradation. ${ }^{32,33} \mathrm{UV}$ radiation may deregulate the procollagen synthesis in human fibroblast by downregulating TGF- $\beta$ type II (T $\beta$ RII) transcription and disrupting the TGF- $\beta /$ Smad signaling. ${ }^{32}$ UV radiation may also cause the downregulation of type 1 procollagen production by upregulating the production of intracellular free radical ROS, such as superoxide anion, hydroxyl radical, singlet oxygen, and hydrogen peroxide. These oxidants will induce the MAPK signaling to activate the transcription factors AP-1 and nuclear factor kappa B (NF$\kappa B)$. MMP production was upregulated by this activation of AP-1 and NF- $\mathrm{KB}$. MMP will then increase the degradation of collagen and elastin in the dermal ECM. ${ }^{10,11,34,35}$ AP-1 also played a role in inhibiting TGF- $\beta$ signaling in photoaged skin. This inhibition will downregulate the production of type 1 collagen precursor (procollagen), thus reducing the formation of new collagens. ${ }^{10,11}$
Meanwhile, in comparison with the group receiving only UVB irradiation, the groups receiving probiotic and UVB irradiation showed significantly higher mean type 1 procollagen level. This confirmed that probiotic supplementation might confer protection from the effects of photoaging and induce the upregulation of type 1 procollagen synthesis in UVB-exposed skin. Previous study also found similar results, where MMP-1 expression was inhibited and procollagen expression in human fibroblast was upregulated by $L$. plantarum supplementation. ${ }^{29}$ Lipoteichoic acid (LTA) from probiotic L. plantarum was found to have the ability to reduce the expression of MMP-1, inhibit the activation of extracellular signal-regulated kinase (ERK) and c-Jun N-terminal kinase (JNK), inhibit the DNA binding activities of AP-1 and NF- $\kappa$ B, thus reducing the generation of ROS induced by UV irradiation and promote type 1 procollagen synthesis. ${ }^{36}$

The current study also found that the group receiving only probiotic showed significantly lower mean type 1 procollagen level in comparison with the group receiving UVB irradiation with probiotic supplementation. This result indicated a possibility that probiotic bacteria may not confer significant antioxidant effects on skin with normal redox balance where the endogen antioxidant system still work properly, and that it may only started to confer significant protective effects on skin that has been subjected to external insults, such as UVB irradiation, causing an increase in free radical production and an imbalance in skin redox environment. ${ }^{37}$ The group receiving only probiotic also showed lower mean type 1 procollagen level in comparison with the control group, albeit with no statistical significance. This difference might be caused by physiological variations in type 1 procollagen production that may be influenced by age, weight and diet of respective mice. ${ }^{38}$

The current study found no adverse effects from probiotic supplementation in all experimental animals. This study is subject to certain limitations. The wrinkle scores was evaluated subjectively based on the assessment of the researcher without using objective measuring instruments or programs that has been validated to evaluate wrinkle scores objectively, such as SWIRL or PRIMOS program capable of objectively quantifying the microstructural geometric condition of the wrinkles. Furthermore, to reduce the variability of the results obtained, part of the skin taken for biopsy should also be predetermined and marked at the place with most UVB exposure for all mice, but the current study has failed to do so. 


\section{Conclusion}

The current study found that $L$. reuteri supplementation may reduce wrinkle formation and increase type I procollagen production in UVB-exposed dorsal skin of male Balb/c mice. However, the long-term effects of $L$. reuteri supplementation on human skin and the efficacy of other probiotic species in comparison with $L$. reuteri warrants further evaluation. Future studies should also utilize more objective methods to evaluate wrinkle formation.

\section{References}

1. Farage MA, Miller KW, Berardesca E, Maibach HI. Psychological and social implications of aging skin: normal aging and the effects of cutaneous disease. In: Farage MA, Miller K, Maibach H, editor. Textbook of Aging Skin. Berlin: Springer-Verlag; 2017. p.1645-56.

2. Farage MA, Miller KW, Elsner P, Maibach HI. Structural characteristics of the aging skin: a review. Cutan Ocul Toxicol. 2007; 26(4): 343-57.

3. Farage MA, Miller KW, Elsner P, Maibach HI. Functional and physiological characteristics of the aging skin. Aging Clin Exp Res. 2008; 20(3): 195-200.

4. Green AC, Hughes MC, McBride P, Fourtanier A. Factors associated with premature skin aging (photoaging) before the age of 55: a population-based study. Dermatology. 2011; 222(1): 74-80.

5. Hwang KA, Yi BR, Choi KC. Molecular mechanisms and in vivo mouse models of skin aging associated with dermal matrix alterations. Lab Anim Res. 2011; 27(1): 1-8.

6. Chiu HW, Chen CH, Chen YJ, Hsu YH. Far-infrared suppresses skin photoaging in ultraviolet B-exposed fibroblass and hairless mice. PLoS One. 2017; 12(3): e0174042.

7. Varani J, Spearman D, Perone P, Fligiel SE, Datta SC, Wang ZQ, et al. Inhibition of type I procollagen synthesis by damaged collagen in photoaged skin and by collagenase-degraded collagen in vitro. Am J Pathol. 2001; 158(3): 931-42.

8. Farage MA, Miller KW, Elsner P, Maibach HI. Intrinsic and extrinsic factors in skin ageing: a review. Int J Cosmet Sci. 2008; 30(2): 8795 .

9. Krutmann J. Pathomechanisms of photoaged skin. In: Farage MA, Miller K, Maibach H, editor. Textbook of Aging Skin. Berlin: Springer-Verlag; 2017. p.121-9.

10. Pittayapruek P, Meephansan J, Prapapan O, Komine M, Ohtsuki M. Role of matrix metalloproteinases in photoaging and photocarcinogenesis. Int J Mol Sci. 2016; 17(6): E868. doi: 10.3390/ijms17060868.

11. Quan T, Qin Z, Xia W, Shao Y, Voorhees JJ, Fisher GJ. Matrixdegrading metalloproteinases in photoaging. J Investig Dermatol Symp Proc. 2009; 14(1): 20-4.

12. Kober MM, Bowe WP. The effect of probiotics on immune regulation, acne, and photoaging. Int J Womens Dermatol. 2015; 1(2): 85-9.

13. Hou C, Zeng X, Yang F, Liu H, Qiao S. Study and use of the probiotic Lactobacillus reuteri in pigs: a review. J Anim Sci Biotechnol. 2015; 6(1): 1-18.

14. Nourazarian SM, Irajian G, Najafi M, Nourbakhsh M, Maleki J, Shabani M. The effects of Lactobacillus reuteri on bone morphogenetic protein- 7 and beta transforming growth factor gene expressions in streptozotocin-induced diabetic rat's kidneys. Pak J Biol Sci. 2012; 15(8): 374-9.

15. Hsu TC, Huang CY, Liu CH, Hsu KC, Chen YH, Tzang BS. Lactobacillus paracasei GMNL-32, Lactobacillus reuteri GMNL89 and L. reuteri GMNL-263 ameliorate hepatic injuries in lupusprone mice. Br J Nutr. 2017; 117(8): 1066-74.

16. Iyer C, Kosters A, Sethi G, Kunnumakkara AB, Aggarwal BB, Versalovic J. Probiotic Lactobacillus reuteri promotes TNF-induced apoptosis in human myeloid leukemia-derived cells by modulation of NF-kappaB and MAPK signalling. Cell Microbiol. 2008; 10(7): 1442-52.

17. Lin YP, Thibodeaux CH, Peña JA, Ferry GD, Versalovic J. Probiotic Lactobacillus reuteri suppress proinflammatory cytokines via c-Jun. Inflamm Bowel Dis. 2008; 14(8): 1068-83.

18. Erdman SE, Poutahidis T. Probiotic 'glow of health': it's more than skin deep. Benef Microbes. 2014; 5(2): 109-19.

19. Levkovich T, Poutahidis T, Smillie C, Varian BJ, Ibrahim YM, Lakritz JR, et al. Probiotic bacteria induce a 'glow of health'. PLoS One. 2013; 8(1): e53867.

20. Goettsch W, Garssen J, de Gruijl FR, Dortant P, van Loveren H. Methods for exposure of laboratory animals to ultraviolet radiation. Lab Anim. 1999; 33(1): 58-67.

21. Kiss I, Chen S, Tramposch KM. The effect of high and low ultraviolet-B dose exposure on the degree of hairless mouse skin wrinkling. Photochem Photobiol. 1991; 53(1): 109-12.

22. Imokawa G, Ishida K. Biological mechanisms underlying the ultraviolet radiation-induced formation of skin wrinkling and sagging I: reduced skin elasticity, highly associated with enhanced dermal elastase activity, triggers wrinkling and sagging. Int J Mol Sci. 2015; 16(4): 7753-75.

23. Bissette DL HD, Orr TV. Animal model of solar aged skin: histological, physical and visible changes in UV-irradiated hairless mouse skin. Photochem Photobiol. 1987; 46(3): 367-78.

24. Kodali VP, Sen R. Antioxidant and free radical scavenging activities of an exopolysaccharide from a probiotic bacterium. Biotechnol J. 2008; 3(2): 245-51.

25. Cinque B, Palumbo P, La Torre C, Melchiorre E, Corridoni D, Miconi $\mathrm{G}$, et al. Probiotics in aging skin. In: Farage MA, Miller K, Maibach H, editor. Textbook of Aging Skin. Berlin: Springer-Verlag; 2017. p.1315-27.

26. Imokawa G. Recent advances in characterizing biological mechanisms underlying UV-induced wrinkles: a pivotal role of fibrobrastderived elastase. Arch Dermatol Res. 2008; 300(Suppl 1): S7-20.

27. Matsuda M, Hoshino T, Yamakawa N, Tahara K, Adachi H, Sobue G, et al. Suppression of UV-induced wrinkle formation by induction of HSP70 expression in mice. J Invest Dermatol.2013; 133(4): 919-28.

28. Im AR, Kim HS, Hyun JW, Chae S. Potential for tyndalized Lactobacillus acidophilus as an effective component in moisturizing skin and anti-wrinkle products. Exp Ther Med. 2016; 12(2): 759-64.

29. Kim HM, Lee DE, Park SD, Kim YT, Kim YJ, Jeong JW, et al. Oral administration of Lactobacillus plantarum HY7714 protects hairless mouse against ultraviolet B-induced photoaging. J Microbiol Biotechnol. 2014; 24(11): 1583-91.

30. Lee DE, Huh CS, Ra J, Choi ID, Jeong JW, Kim SH, et al. Clinical evidence of effects of Lactobacillus plantarum HY7714 on skin aging: A randomized, double blind, placebo-controlled study. J. Microbiol Biotechnol. 2015; 25(12): 2160-8.

31. Suk JH, Park JA, Kang SM. Effects of Lactobacillus reuteri Intake to Facial Skin Condition of Women. J Kor Soc Cosm. 2018; 24: 66170. 
32. Quan T, He T, Kang S, Voorhees JJ, Fisher GJ. Solar ultraviolet irradiation reduces collagen in photoaged human skin by blocking transforming growth factor-beta type II receptor/Smad signaling. Am J Pathol. 2004; 165(3): 741-51.

33. Zouboulis CC, Makrantonaki E. Clinical aspects and molecular diagnostics of skin aging. Clin Dermatol. 2011; 29(1): 3-14.

34. Brenneisen P, Sies H, Scharffetter-Kochanek K. Ultraviolet-B irradiation and matrix metalloproteinases: from induction via signaling to initial events. Ann NY Acad Sci. 2002; 973: 31-43.

35. Fisher GJ, Wang ZQ, Datta SC, Varani J, Kang S, Voorhees JJ. Pathophysiology of premature skin aging induced by ultraviolet light. New Eng J Med. 1997; 337(20): 1419-28.

36. Hong YF, Lee Hy, Jung BJ, Jang S, Chung DK, Kim H. Lipoteichoic acid isolated from Lactobacillus plantarum down-regulates UVinduced MMP-1 expression and up-regulates type I procollagen through the inhibition of reactive oxygen species generation. Mol Immunol. 2015; 67(2 Pt B): 248-55.

37. Nwanodi O. Skin protective nutraceuticals: the current evidence in brief. Healthcare (Basel). 2018; 6(2): E40. doi: 10.3390/ healthcare6020040.

38. Kavitha O, Thampan RV. Factors influencing collagen biosynthesis. J Cell Biochem. 2008; 104(4): 1150-60. 